Journal of Economics and Behavioral Studies

Vol. 4, No. 3, pp. 172-179, Mar 2012 (ISSN: 2220-6140)

\title{
Influencing Factors of Job Satisfaction in TechnicalOrganization
}

\author{
Muhammad Ibrahim, *Sayed Fayaz Ahmed, Nadir Khan, Yasser Khan, Zahid Mahmood Awan, \\ Muhammad Khalil Shahid, Abdul Kareem \\ Institute of Communication Technologies, NWFP University of Engineering \& Technology, Peshawar, Pakistan \\ *fayaz_sayer@yahoo.com
}

\begin{abstract}
The aim of this research is to find out the core factors, which have a strong impact on Job Satisfaction in Technical Organizations in Pakistan. This study discusses the main variableslike Effective Recruitment, Rewards, and Personality of employees and Role of Leadership and their effect on job satisfaction. First hand, data was used in the research and some important recommendations were made for the improvement of Job Satisfaction of employees working at Ufone. It is expected that this study will make comprehensive note to the environment of Ufone especially and every other organization in general, how to make their working environment acceptable to the employees.
\end{abstract}

Keywords:Recruitment, Organizational Rewards, Personality, Leadership behavior and Job Satisfaction

\section{Introduction}

In most organizations usually and in technical organization particularly, the most important issue is that of the Job Satisfaction but it is least understood unfortunately. There are a lot of motivations theories which, without doubt is very essential for understanding the work place and are very helpful also but as human nature is very complex and it needs a lot to study and examine it additionally (Sperof, 1955).Mostly everyone in workplace is aware of his or her important role that job satisfaction play in the industrial climate (Sperof, 1955).In this research that researchers are trying to investigate different factors, which influence Job Satisfactionand seek ways to retain employees and reduce the turnover rate (Mhlathieu \& Hamel, 1989). Today's workers expect more than just an hourly salary; they want additional considerations that will enrich their lives. These considerations in an employment setting are called employee benefits. Benefits, other than pension distributions, paid to employees during their retirement years.There are many factors affecting Job satisfaction, some of them being considered are personality of individuals, proper recruitment, rewards(Temnitskii, 2001) and leadership characteristics. It is seemed that employees are not fully satisfied with their jobs and it is so sad to know that many of them compromise the situation where they are in. Therefore, it is said that satisfied employees have positive impact on any organization. Keeping it in mind, proper recruitment of individuals plays its vital role in development of an organization. An effective reward system offered by a firm and leadership behavior can play their most important role towards employee's job satisfaction.

Job satisfaction is a feeling of mind of a person and his assessment about his job, and this sensitivity is related to the individual's unique status like as needs, ethics and hopes. The persons will assess their work regarding the factors being considered more important by them(Buitenbach and De Witte, 2005). Some researchersstudied the importance of affiliation between personality and job satisfaction based onfivecharacteristic model of personality. They agreed that work related to individual's personality factor is more helpful to attain job satisfaction(Henderson, 2003).This research will further investigate the effect of different factors influencing job satisfaction of employees. The research will be conducted on diverse organizational spectrum to cover technical companies in public and private sector. The study will benefit the organizations to decide to either give high monthly salaries or make some other plans to increase the job satisfaction.The remarkable area of discussion in the field of Management, Organization Behavior and Human Resource Management is the job satisfaction. In literature review, the association between different factors; recruitment, organizational reward, personal characteristics, leader behavior, and their impact on job satisfaction will be discussed. One research stated job satisfaction as the output of the individual's assessment level that how the work environment fulfill their needs (Dawis and Lofquist, 1984) while one another 
research stated it as a mental satisfaction which comes from achieving desired goals (Locke, 1969). The affective action and very positive attitude of individuals towards the work setting, shows the satisfaction of job, which is ever most area of research by researcher and the administration of the organizations (Sekaran, 1989). Satisfaction of job is the combination of events and conditions that employees show on work place. If the job of an individual is interesting, the reward offered by the firm is good; lot of opportunities for promotion, supportive supervisor, and friendly coworker then such a situation provides the sense of job satisfaction (Brief, 1998).

By understanding the factors for job satisfaction, the managers will enforce as more elements as possible to maximize it in their organizations for increasing effectiveness and productivity. The results of this research will solve many problems arising from the job satisfaction in the employees of technical organization. In addition, it will make a significant contribution to the managers to run their organization in a proper way regarding to the main jobs issues of the technical employees.

Following are the main objectives:

- To find out the recruitment and selection procedures affect job satisfaction.

- To find out the influence of rewards offered by firms on job satisfaction.

- To find out the individual personality impacts on job satisfaction.

- To find out the impacts of leadership characteristics on job satisfaction

- To develop a new model.

\section{Literature Review}

Job Satisfaction: Job Satisfaction is the most important area of study in Organizational Behavior and Management. In this article latter, it will be discussed with the relationships of different factors like recruitment, organizational reward, personal characteristics and leadership behavior. In the recent years lot of economists have great attention towards the subject of job satisfaction.Job Satisfaction is defined as the evaluation of individual's assessment level that how the work environment fulfill their needs (Dawis and Lofquist, 1984). It is very necessary for achieving the organizational goal if it is in the shape of mental satisfaction. Satisfied employees will favor the betterment of organization and work for healthier and healthier organization (Locke, 1969). In another words, it is the happiness value of workers to work and intensity of performing their job duty (Ramayah, Jantan and Tadisina, 2001).Some researchers studied that job satisfaction plays the role of motivation for individuals (Rao, 2005). Therefore, the individuals put their best efforts for the favor of the company. While some other researchers said that the individual's happiness with their job are more productive for the organization and result commitment with the organization (Buitenbach and De Witte, 2005).Positive attitude of workers towards the work, organization, shows the level of job satisfaction and is a vast area for researches (Sekaran, 1989). Satisfaction of job is the combination of events and conditions that employees show on work place. If the job of an individual is interesting, the reward offered by the firm is good, supportive supervisor, these parameters provide sense of job satisfaction (Brief, 1998).

Effective Recruitment: The activities undertaken by the HRM for the attraction of more and more potential and competent job candidates who are likely to fill the required job duties and to contribute in achieving the organizations objectives is called the process of recruitment (Swanepoel, Erasmus, Van Wyk \& Schenk, 2003). The process in which the task is to determine the best match employees with some jobs duties is called selection process. Recruitment must be done according to the policy and regulation of an organization, which should satisfy the long-term strategic goals and objectives of the organization. The policy of the firm must be clear and to make it more clear all the level of employees must be considered to participate in the organizational recruitment policy for making it more effective and efficient (Swanepoel, Erasmus, Van Wyk \& Schenk, 2003).HRM have the function of providing mutuality between the employees and organizational needs. Most of the jobs need a person with a special personality while some jobs need not (Dale, 2006). Some firms uses brochures which have full description of work, some other uses video films to aware its employees from their duties, while some arranges visits for the new employees (Champoux, 2006).For an effective recruitment process there should be enough details of job description and specification (Dale, 2006). Interview has also a great impact on the process of recruitment and it is necessary to make natural environment for taking the job interview, it will ensure the job employee easy and he/she can perform well 
during answering to questions (Furnham, 2008). Questions directly related to job and panel interview will make the process more fruitful and beneficial (Swanepoel, Erasmus, Van Wyk \& Schenk, 2003). Over qualified candidate should also be avoiding. Better recruitment policy is helpful for better and suitable employees, who will be more satisfied with jobs and working place. In addition, if an organization has weak recruitment process it will get weak employees, which will be dissatisfied, with jobs and less committed to their organization. Based on this study, we have derived the following hypothesis.

Hypothesis 1: Effective recruitment has positive effect over the job satisfaction

Rewards: Organizations want to motivate its employees for better performance and to achieve the organizational objectives and goals. For this aim, a reward system is introduced in each organization to attract, to produce more commitment and to motivate employees of the organization. It seems an easy system but it is quite difficult to arrange and deal with the system for receiving the desired objectives (Martin, 2005). Employees of any organization also have certain expectation from their organization, which includes fail pay policy, safety in work place and security of job and honest management (Ali \&Ahmed, 2008). In contrast to this management, also expect more from its employees. The organization expects that its employees perform better and reliably the actual assigned task. Therefore the management should develop its policy and regulation as to fulfill the needs of its employees and keep them satisfy, achieve the objectives of the organization, better performance and productivity. In order to attract and keep employees motivated, organizations usually applies various techniques. In other words, if the company wants to keep its employees motivated, it should first find the needs, level and desire of its employees and then introduce a reward system for it, so that the employees may be kept satisfied with their actual desires and needs, which will result more satisfaction, and better performance and will be more help full for achieving the organizational objectives and satisfaction of jobs (Hitt et al., 2006). Rewards plays and vital role and are very necessary for driving the employees to any kind of job. Organizations should also facilitate its employees and working environment with proper cooling and heating systems, safety measure, listening to the complaints of employees, fair treatment and vice versa. This will also add measure to the satisfaction of job (Hitt et al., 2006). In short, better reward system will keep employees more satisfied and committed to the organization, which will help in achieving the organizational objectives. After studying the above literature, we have supposed to draw the following assumption for our study.

Hypothesis 2:Organizational reward increases the job satisfaction

Personality: Personality is a very complex in nature as it seems to be. Alport defines it as "Personality is a lively organization inside an individual which creates special type of behavior, feelings and thoughts" (Hewstone, 2005). Talent, hard work or job skills are not sufficient for an individual to work in a specific environment. There is also some other factors which also affect the job activities, these factors includes communication and interpersonal skills, self-control and emotions are the most important (Werner, 2007).According to a study, the behavior or personality type comes from parents genetically (Champoux, 2006). While many other researchers believes that it comes partially from parents and partially learned from the social environment, and it is the interaction of individual internal qualities and the external environment. After a large and deep research process the personality types has been divided into five main types in Big Five Model (Werner, 2007). As it is unpredictable to find suitable employees for an organization, because education and skills are not the only parameter to measure the level of job satisfaction. Therefore a test is conducted for measuring the mental level through specific process for finding the characteristic like ability (Martin, 2005). Some researchers also believes that it type of personality change with the outside situations to some particular extent. The measurement of personality has the aim to find the best-fit employees and best matched employees with specific jobs (Hitt et al., 2006).Personality type has also a great effect over career. Therefore, if the type of personality type contradicts the determinants of job, the employee will be dissatisfied with his/her job. The above literature survey indicates that the personality type have great impact on the level of satisfaction of job. Therefore, it is important that the type of personality should be suitable for job, the candidate is hired for. This review of study indicates that Personality type has a great impact over the satisfaction of job, so we assume the following hypothesis.

Hypothesis 3:Personal characteristics increase the job satisfaction

Role of Leadership: It is a process during which one person influences other persons to do work happily and devotedly to achieve organizational objectives and goals is called leadership. It is not limited or restricted to a 
special position, special person, or special level in an organization, but it can appear at any level. It is very necessary for obtaining the organizational goals, therefore organization are making and adopting, such a culture where there is leadership by introducing self-managed teams (Werner, 2007). "People don't quit companies. They quit managers" said by a researcher (Howe, 2003). Now a days peoples are seeking such an organization where they a respect and ear to hear their voice, where there work is under consideration and recognized as a positive contribution. This can be highly affected by their immediate manager or boss, who has always a sight over their work. If the supervisor values the work of the employee, he will be more satisfied and intended to work (Howe, 2003). Also when the supervisor keep the employee or sub ordinate update with the happening of the organization and keep them aware from the rules and regulation, it will create a scene of accomplishment in the heart of the worker and he start to believe that the organization has more value and fairness for him (Ruppel and Harrington, 2000).Most of the human resource managers believe that employees leave their organizations due to better employment opportunities in the market, stressful working environment, less promotion opportunities, less organizational fit and poor or incompetent management (Howe, 2003). When a worker believes that his boss or manager is honest with him and there is a positive relationship between them, there will be a positive effect on job satisfaction (Dirks and Ferrin, 2002); Kwaku and Li, 2002).Therefore, better management will be more helpful to provide them better employment and keep them more satisfied with their jobs, so that there will be lessen leave process and more commitment. Based on the literature study, we want to assume that:

Hypothesis 4: Role of Leadership has positive effect on the job satisfaction

\section{Figure 1: Structural Model: Schematic Diagram for Relation between the Variables}

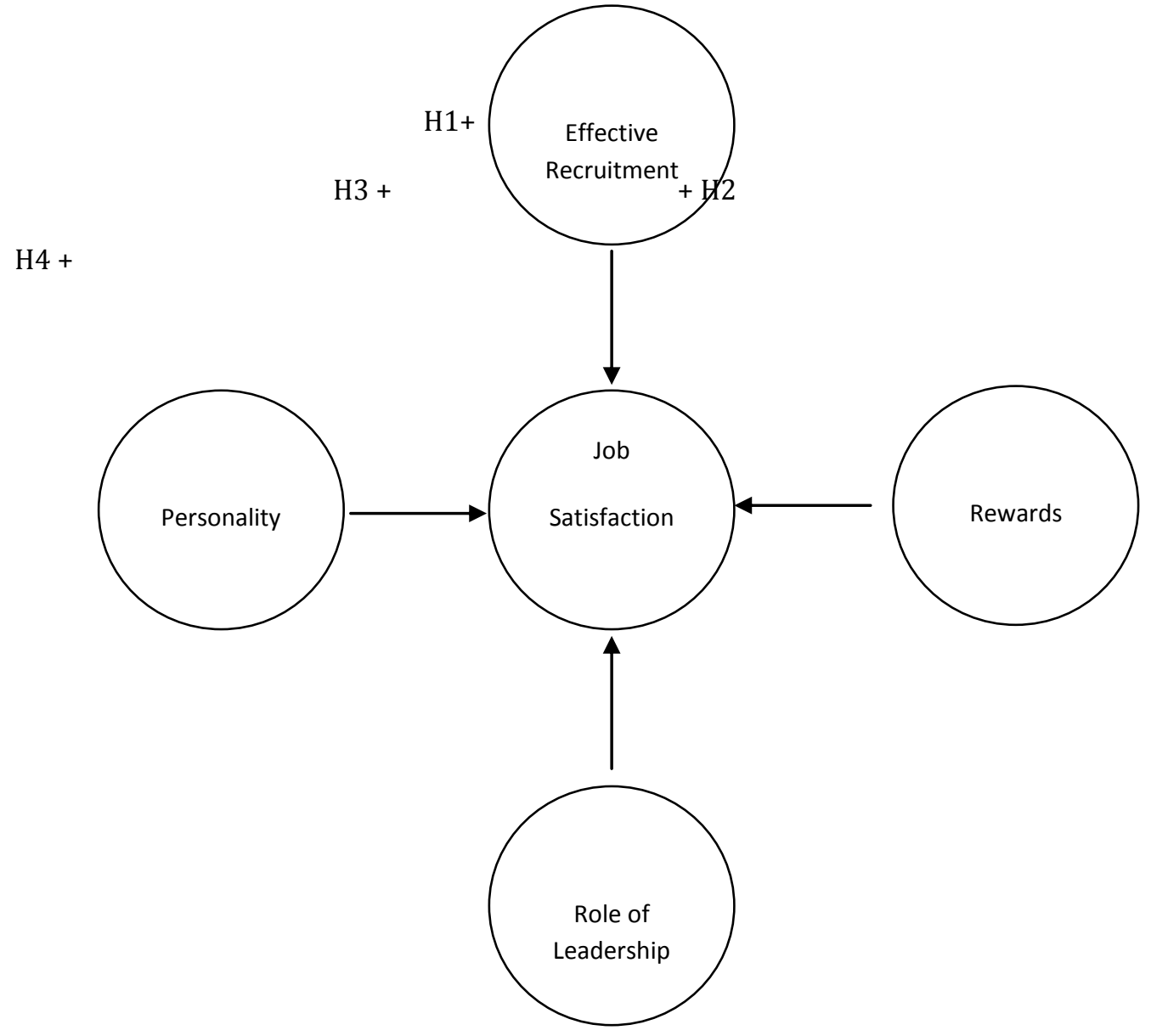

\section{Methodology}

To find out best possible solution of the main objectives, it was necessary to investigate the perception of the employees of selected company UFONE. The questionnaire survey method was selected for response from 
employee of selected company due to less time consuming.For this purpose, questionnaires were developed which had strong inter relationship and validity. After success, development of questionnaire different type of distributing media was used. The respondent having electronic mail the questionnaire was sent through email to them. However, mostly questionnaires were handed distributed. The population of the research was the employees of UFONE working in Islamabad. Then, the questionnaires were distributed among different level of employees of UFONE to respond.300 copies of questionnaires were distributed among the individuals of almost all departments in UFONE and 270 completed copies were received back.The SPSS Software was used to analyze the data. The questions were used to know the influence of variables on job satisfaction. The closed ended questions were anchored by a 5-points scale range from (1) strongly agree to (5) strongly disagree. In addition, it was analyzed that at up to how much level people are satisfied. The Regression was done to know the impact of independent variables over dependent variables. The results obtained from analysis are discussed in next part.

\section{Analysis and Results}

Reliability statistics: Reliability statistics test is applied in order to make a reliable research, to know the validity of questionnaire used for research; we apply such a test before distributing it to the respondents to give their response. The results shown in above table provide us the reliability and validity of our questionnaire. The value of Cronbach Alpha is 0.722 shows that the questionnaire is valid and can be used for suitable results of research.

ANOVA: The following table defines the ANOVA about the samples based on between groups and within groups. The Leader Behavior is significant, having the significant value of 0.001 with $F$ value $=8.982$. Similarly Organizational Reward has significant response with significant value of 0.000 and $F$ value $=6.66$. There is significant response shown by Personal Characteristics having the significant value 0.020 and $\mathrm{F}$ value $=5.464$. The Recruitment and Job Satisfaction are significant with significant values of 0.697 and 0.001 having the $F$ values 0.151 and 0.112 . These results show the big variance among the different research factors.

Table 1: ANOVA Test

\begin{tabular}{llclccc}
\hline & & Sum of Squares & Df & Mean Square & F & Sig. \\
\hline LB & Between Groups & 18.967 & 1 & 4.767 & 8.982 & .001 \\
& Within Groups & 83.998 & 268 & .497 & & \\
& Total & 102.965 & 269 & & & .000 \\
ORD & Between Groups & 6.229 & 1 & 1.229 & 6.666 & \\
& Within Groups & 38.938 & 268 & .243 & & .020 \\
& Total & 44.167 & 269 & & & \\
PC & Between Groups & 1.755 & 1 & 1.755 & 5.464 & .697 \\
& Within Groups & 86.085 & 268 & .321 & & \\
& Total & 87.840 & 269 & & & \\
RT & Between Groups & .056 & 1 & .056 & .151 & \\
& Within Groups & 99.423 & 268 & .371 & & \\
& Total & 99.480 & 269 & & & \\
JS & Between Groups & 5.027 & 1 & 1.427 & .112 & \\
& Within Groups & 70.531 & 268 & .445 & & \\
& Total & 75.559 & 269 & & & \\
\hline
\end{tabular}

Correlation Analysis:The purpose of correlation analysis is to determine the relationship between two variables. We also may find that 1 - there is positive correlation, 2- there is negative correlation, 3- there is no correlation. The following above shown table indicates the Correlation among different variables, which have been used for our research. The value of $\mathrm{P}=0.05$ to 0.01 shows that there is positive significant correlation among the variables. Therefore, by using above correlation table we check the relationship among the variables, which were also used in formulation of our hypothesis in our research. 
Table 2:Correlation Analysis

\begin{tabular}{|c|c|c|c|c|c|c|}
\hline & & LB & ORD & PC & RT & JS \\
\hline \multirow[t]{3}{*}{ LB } & Pearson Correlation & 1 & & & & \\
\hline & Sig. (2-tailed) & & & & & \\
\hline & $\mathrm{N}$ & 270 & & & & \\
\hline \multirow[t]{3}{*}{ ORD } & Pearson Correlation & $.366(* *)$ & 1 & & & \\
\hline & Sig. (2-tailed) & .000 & & & & \\
\hline & $\mathrm{N}$ & 270 & 270 & & & \\
\hline \multirow[t]{3}{*}{ PC } & Pearson Correlation & $.210(* *)$ & $.425\left(^{* *}\right)$ & 1 & & \\
\hline & Sig. (2-tailed) & .001 & .000 & & & \\
\hline & $\mathrm{N}$ & 270 & 270 & 270 & & \\
\hline \multirow[t]{3}{*}{ RT } & Pearson Correlation & $.384(* *)$ & $.376(* *)$ & $.450(* *)$ & 1 & \\
\hline & Sig. (2-tailed) & .000 & .000 & .000 & & . \\
\hline & $\mathrm{N}$ & 270 & 270 & 270 & 270 & \\
\hline \multirow[t]{3}{*}{ JS } & Pearson Correlation & $.521(* *)$ & $.775\left(^{* *}\right)$ & $.200\left(^{* *}\right)$ & $.483(* *)$ & 1 \\
\hline & Sig. (2-tailed) & .000 & .003 & .006 & .002 & \\
\hline & $\mathrm{N}$ & 270 & 270 & 270 & 270 & \\
\hline
\end{tabular}

** Correlation is significant at the 0.01 level (2-tailed)

* Correlation is significant at the 0.05 level (2-tailed)

Hypothesis No.1 Effective recruitment have positive affect over the job satisfaction: The value (.483(**), $\mathrm{p}=.002$ ) from above mentioned table of correlation analysis illustrates that there is positive significant relationship between Effective Recruitment and Job Satisfaction. Therefore, it has been proved that if the recruitment and selection process is clearly defined and on merit, the job satisfaction is raised in employees of UFONE.

Hypothesis No. 2: Organizational Rewards increases job satisfaction: There is positive significant relationship between Organizational Rewards and Job satisfaction as it can be clearly seen by the value $\left(0.775\left(^{* *}\right), \mathrm{p}=.003\right)$ mentioned in above correlation table. It defines that when employees are well rewarded their satisfaction level is increased.

Hypothesis No. 3: Role of leadership has positive effect on the job satisfaction: The correlation table shows that there is also positive significant relation between Leader Behavior and Job satisfaction having the value $\left(0.521\left(^{* *}\right), p=.000\right)$ which states that if the behavior of supervisor is good the employees feel happy to do any challenging work.

Hypothesis No. 4: Personal characteristics increase job satisfaction: The value $(0.200(* *), p=.003)$ from correlation table indicates that there is a positive significant relation between Personal Characteristics and Job satisfaction. Therefore, the research proved that if the individual's attitude towards the job is effective and positive the satisfaction level is increased.

Regression Analysis of the Model: The regression among the different variable of the research is given in the table. 
Table 3: Regression analysis

\begin{tabular}{llllclll}
\hline & Model & B & Std. Error & T-Statistics & Sig. & F & P-value \\
\hline 1 & (Constant) & 3.445 & .222 & 15.51 & .000 & 1.063 & 0.003 \\
& LB & .969 & .190 & 5.113 & .000 & & \\
& ORD & 2.740 & .708 & 3.733 & .003 & & \\
& PC & .852 & .312 & 2.844 & .006 & & \\
& RT & .931 & .185 & 4.826 & .002 & & \\
\hline
\end{tabular}

Predictors: (Constant), RT, ORD, LB, PC

B Dependent Variable: JS

\section{Conclusion}

The research concluded some important points about the various factors and Job Satisfaction in Ufone. The major points of conclusion as given in the following lines:The leadership characteristics of the managers are necessary for the Job Satisfaction in the organization of Ufone. It is necessary for the organization to produce good leadership characteristics in its employees. Presently its employers do not show such characteristics, which are necessary to help their employees to remain satisfied in the organization.The reward system of organization is also not as good as the employees need to be. Employees believe that they possess all the necessary characteristics, which are needed for job Satisfaction. It means that there is no or less problem from the characteristics of employees, which leads them to dissatisfaction in the organization.The recruitment process has also a great impact on job satisfaction in Ufone. Ufone needs to develop and promote the process because currently the employees are not so much satisfied as it needs to be.

Recommendations: After completing the research process, we have the following recommendation:

- Technical Organizations in Pakistan needs to specify the actual duties to technical and non-technical workers in their organization in such a manner that will ensure to decrease professional conflicts among the employees.

- Technical organization's employees also need balanced and unbiased distribution of rewards, not only in form of material like money, but also in spiritual form like praising and acknowledging.

- It is also necessary for the organizations, to make it recruitment process as affective as possible, which not only help in hiring the best possible employee but an employee with good and universal acceptable characteristic also.

Practical Amplification: This research study will make a significant contribution to the issue of Job Satisfaction in the technical organizations. This will help and guide the management to know the basics of problems in their organization and will increase the power of decision. It has a strong claim that it will minimize the different conflicts arising from Job Dissatisfaction.

Limitations: Yet this research has a claim to perfection, there is some limitations too regarding to this research. Initially our research survey was limited to the employees of Ufone and we have not included any other Technical organization. Secondly, the research was limited to the region of Islamabad/Pindi only. Thirdly, there are many other important variables, which have influence over Job Satisfaction, which were not considered by us in this research.

\section{References}

Ali, R. \& Ahmed, M.S. (2008). The Impact of Reward and Recognition Programs on Employee's Motivation And Satisfaction A Co relational Study [Online]. Available from: http://www.wbiconpro.com/22.Reena.pdf (accessed: 26 June 2011).

Brief, A. P. (1998). Attitudes in and Around Organizations. Thousand Oaks, CA: Sage.

Buitenbach, J.H. \& De-Witte, H. (2005). Job insecurity, extrinsic and intrinsic job satisfaction and affective organizational commitment of maintenance workers in a parastatal. South African Journal of Business Management, 36(2), 27-39. 
Champoux, J.E. (2006). Organizational Behavior: Integrating Individuals, Groups and Organizations. New Mexico: Thomson South Western.

Dawis, R.\& Lofquist, L. (1984). A psychological theory of work adjustment. Minneapolis, MN: University of Minnesota Press.

Dale, M. (2006). The Essential Guide to Recruitment. London: Kogan Page Limited.

Dirks, K. T. \&Ferrin, D. L.(2002). Trust in Leadership: Meta-Analytic Findings and Implications for Research and Practice.Journal of Applied Psychology, 87(4), 611-628.

Furnham, A. (2008). Head and Heart Management. New York: Palgrave Macmillan.

Greenberg, J. \& Baron, R.A. (1995). Behavior in organizations. London: Open Books Publishing Ltd.

Hewstone, M., Fincham, F. D. \& Foster, J. (2005). Psychology. Australia: Blackwell Publishing.

Hitt, M., Miller, C. \& Colella, A. (2006). Organizational Behavior: A Strategic Approach. Danvers: Hermitage Publishing Services.

Howe, T. (2003). To Stay or Leave: Job satisfaction and turnover [Online]. Available from: http://www.charityvillage.com/cv/research/rhr6.html.

Kwaku, A. G. \&Li, H.(2002). When Does Trust Matter? Antecedents and Contingent Effects of Supervisee Trust on Performance in Selling New Products in China and the United States.Journal of Marketing, 66(3), 61-81.

Locke, E. A. (1969). What is job satisfaction? Organizational Behavior and Human Performance, 4, 309-336.

Martin, J. (2005). Organizational Behavior and Management. London: Thomson Learning.

Mhlathieu, J. E.\& Hamel, K. (1989). A causal model of the antecedents of organizational commitment among professionals and nonprofessionals. Journal of Vocational Behavior, 34, 299-317.

Ramayah, T., Jantan, M.\& Tadisina, S.K. (2001). Job satisfaction: empirical evidence for alternatives to JDI.32nd Annual Meeting of Decision Sciences Institute Conference, Track OB2, San Francisco: USA.

Rao, S. P. (2005). Essential of HRM \& Industrial Relationships,(480 to 482).

Ruppel, C. P. \&Harrington, S. J.(2000). The Relationship of Communication, Ethical Work Climate, and Trust to Commitment and Innovation.Journal of Business Ethics, 25(4), 313-328.

Speroff, B. J. (1955). Job Satisfaction and Interpersonal Desirability Values. Sociometry, 18(1), 69-72.

Swanepoel, B., Erasmus, B., Van-Wyk, M. \&Schenk, H. (2003). South African Human Resource Management: Theory and Practice (3rd Edition). Cape Town, Juta.

Sekaran, U. (1989). Paths to the Job Satisfaction of Bank Employees. Journal of Organizational Behavior, 10 (4), 347-359.

Temnitskii, S.(2001). Job Satisfaction and Satisfaction with Life. The Institute of Sociology, Russian Academy of Sciences, 40, $6-12$.

Werner, A. (2007). OrganizationalBehavior: A contemporary South African perspective. Pretoria: Van Schaik. 